\title{
APPLYING VIDEO-STIMULATED REFLECTION AS A LEARNING STRATEGY TO ENHANCE EFL STUDENTS' SPEAKING PERFORMANCE
}

\author{
1Dian Safitri, ${ }^{2}$ Ferawati, ${ }^{3}$ Herri Mulyono \\ 1,2,3University of Muhammadiyah Prof. DR. HAMKA, Jakarta \\ Ferawati1996@gmail.com
}

\begin{abstract}
This qualitative study aimed to examine video-stimulated reflection as a learning strategy to enhance English as a foreign language (EFL) students' speaking performance. The data from six students majoring in English Education, in a private university in Indonesia were collected through students' reflection journals and semi-structured interviews. The results were analyzed using thematic analysis. The findings of the current study indicate that video-stimulated reflection has encouraged students to improve their speaking ability. More specifically, the key targets for enhancing the performance of students' in speaking to others on a daily basis were voice control, body language, and effectiveness.
\end{abstract}

Key Words: video-stimulated reflection, speaking strategy, EFL students

\section{INTRODUCTION}

Reflection is a process characterized by self-awareness, understanding a situation and gain new developments to inform future actions. First suggested by Carlone, Scott, and Lowder (2014), they believe that the concept and practice of using reflection are considered as a possible way of exploring students' ability to improve their speaking. While Boud (1998) stated, reflection is a "highly context-specific" process in which deep reflection plays a key role in building appropriate processes, creating a supportive environment and establishing reciprocal communication. In addition, most studies have emphasized that teaching communication skills will emphasize the need for students to be engaged in purposeful reflection on their shortcomings, and they "compelled to do much of their own work" (Boyle, 1996). As a result, the application of video-stimulated reflection as a learning strategy can help students to facilitate their speaking performance. It has also found to have several positive impacts such as provide opportunities to speak, scaffold learning and provide speaking language resources.

In the 21st century, Li and Peng (2018) define that our commonly perceived barriers to reflective learning include: lack of time, undervalued reflection by teachers, lack of reflective awareness among students, and underdeveloped reflective ability, limited experience using resources for reflection, fear of failure and lack of feedback. The primary aim of their research was to explain how students could be directed to participate in reflective practice and to explore how the project will impact students' ability to reflect and assess the learning experience.

In addition, Mary (2013) argues that students are seldom taught how to communicate their knowledge by reflecting. A review of the literature reveals that in learning English, there has been a lack of empirical studies on the effects of video-reflection about students' 
experiences. McNulty, A., and Lazarevic (2012) highlight the role of video reflection, which can promote EFL students' pronunciation and presentation performance. Findings from the study showed that the use of video reflection as an instructional tool might support EFL students' speaking performance.

With this regard, the primary aim of the current research is to explore how EFL students could be directed to engage in reflective practice and to explore how the project will impact their ability to reflect and assess the learning experience. Particularly, we attempt to provide further qualitative evidence to support the advantages of using video stimulated reflection a learning strategy to enhance EFL students' speaking performance at a private university in Jakarta. The research questions are followed:

1. Does students' video-stimulated reflection strategy help students enhance their speaking performance?

2. To what extent does students' video stimulated reflection strategy help to enhance their speaking performance?

The goal of this study is to analyze the use of video-stimulated reflection as an instructional tool in speaking performance of EFL students.

\section{PREVIOUS STUDY}

Many scholars have certified that video-stimulated reflection preserves beneficial impact on students' learning. Several studies s of implementing videos-stimulated reflection in education have been published. Kaur, Yong, Zin, N. M., and DeWitt (2014) present the potential of using videos-stimulated reflection to retain subject content, stimulate the cognitive aspects of language learning, and to contextualize learning. There were Five ESL experts: one from Malaysia's Curriculum Development Center, one expert in the field of education, and three lecturers from tertiary institutions who carried out studies exploring the impact of implementing video-stimulated reflection. These scholars collected the qualitative data through interview. Overall, these studies revealed some evidence to indicate the propitious effects that can assist students to (a) keep the topic content learned (b) help to put learning in perspective (c) stimulate the cognitive dimension of ESL classroom learning, and (d) control on using videos in the ESL classrooms as a teaching and learning resource. The results indicated that the use of videos in the ESL classroom could cognitively stimulate learning and be an effective instructional tool at the same time (Kaur, 2014).

Yasuko et al. (2014) demonstrate how the use of video works by watching the performance of students speaking in public. Their study employed a mixed-method design. The participants were freshmen from Japan $(\mathrm{N}=24)$ who enrolled in English communication classes. Before the second and third presentations, one group represented more proficient students, and the other group represented less proficient students in speaking. The result turns out to be similar to several findings from a replication study by Okada et al. (2017). The results suggested significant performance and group interaction were observed, specifically in peerreviewed scores, and this order of model viewing sequence (i.e., observing on more and less proficient students) appears to boost a positive impact on student performance.

Another case comes from Li and Peng (2018) who examine the use of video-stimulated reflection to facilitate a reflective practice of oral presentations by EFL students. The participants of this study were 30 first-year students. The researchers collected data through a focus group interview and students' reflective journal. Then a systematic, organized, and student-centred reflective learning project was developed and implemented to promote 
reflective practice among students across four main stages: Stage 1: the creation of realistic learning scenarios. Stage 2: self-reflection of scaffolding. Stage 3: reflecting collaboratively for alternative solutions. Step 4: summarizing the experience of reflection. Findings confirmed that a video-stimulated reflective learning project could reinforce the intensity and complexity of the reflective entries of the students, and contribute to their positive assessments of the project.

Further, Yasuko et al. (2014) mention that reflection is able to increase students' awareness of themselves or others and improve their own community speaking skills in EFL classes. Li, A., and Peng (2018) also discovered that the project has accommodated positive effects and benefit for the students' reflectivity and perceived learning abilities. Collectively, these studies' outline that was applying video-stimulated reflection was proofed to arouse students' speaking performance, make the learning more efficient and flexible. Even watching their speaking performance on a recorded presentation had enabled students identified both the strengths and weaknesses of their speaking and accordingly improve their speaking ability.

The studies mentioned above have reported a number of beneficial impacts of applying videostimulated reflection for students' speaking performance. The evidences were: 1 . videos can be an effective tool to help them develop their second language, 2 . students were more comfortable to perform in front of the camera than their own teachers, 3. improve performance of their speaking skills. Kaur, D., Yong, E., Zin, N. M., and DeWitt (2014) have identified that these studies provide important insights that the use of video as an instructional tool could benefit ESL learners.

\section{RESEARCH METHODOLOGY}

\section{Design and participant}

In this present study, a qualitative method used to gain insight into students' perceptions, as researchers were interested in bringing experiences and opinions of students about the results of their video-stimulated reflection. Six English education students who had taken a speaking course participated in this study. In essence, the students who met the selection requirements were under these considerations: (1) a student who conducted lectures in Jakarta, (2) a student who already took a speaking class, and willing to participate in this research. Their backgrounds are detailed in Table 1.

Table 1. Background of participants

\begin{tabular}{|c|c|c|c|c|c|}
\hline Code & Name* & Province & Age & Sex & Education \\
\hline Student 1 & Rafi & Jawa Barat & 22 & $\mathrm{M}$ & Bachelor's degree \\
\hline Student 2 & Joni & Banten & 23 & $\mathrm{M}$ & Bachelor's degree \\
\hline Student 3 & Rizki & Jawa Barat & 22 & $\mathrm{M}$ & Bachelor's degree \\
\hline Student 4 & Tama & Dki Jakarta & 22 & $\mathrm{M}$ & Bachelor's degree \\
\hline Student 5 & Ervinda & Jawa Barat & 22 & $\mathrm{~F}$ & Bachelor's degree \\
\hline Student 6 & Khansa & Jawa Barat & 22 & $\mathrm{~F}$ & Bachelor's degree \\
\hline
\end{tabular}

*The participants have been given pseudonyms

Received August 11, 2020; Revised August 20, 2020; Accepted September 7, 2020 


\section{DATA COLLECTION AND ANALYSIS}

Based on the classification of McNulty, A., and Lazarevic (2012), this project involves the use of video technology in language classrooms and is based on EFL students who play roles as video script creators and video content creators. In principle, this research project addresses a practical problem identified to speaking at a private university where video-stimulated reflection was applied as a learning strategy to enhance English as a foreign language students' speaking performance. When collecting the data using the method of Okada et al., (2017) , the four phase procedure was adopted, but the difference is the previous journal focused on research in the form of groups and this research focused on the form of individuals, as shown in Figure 1 below:

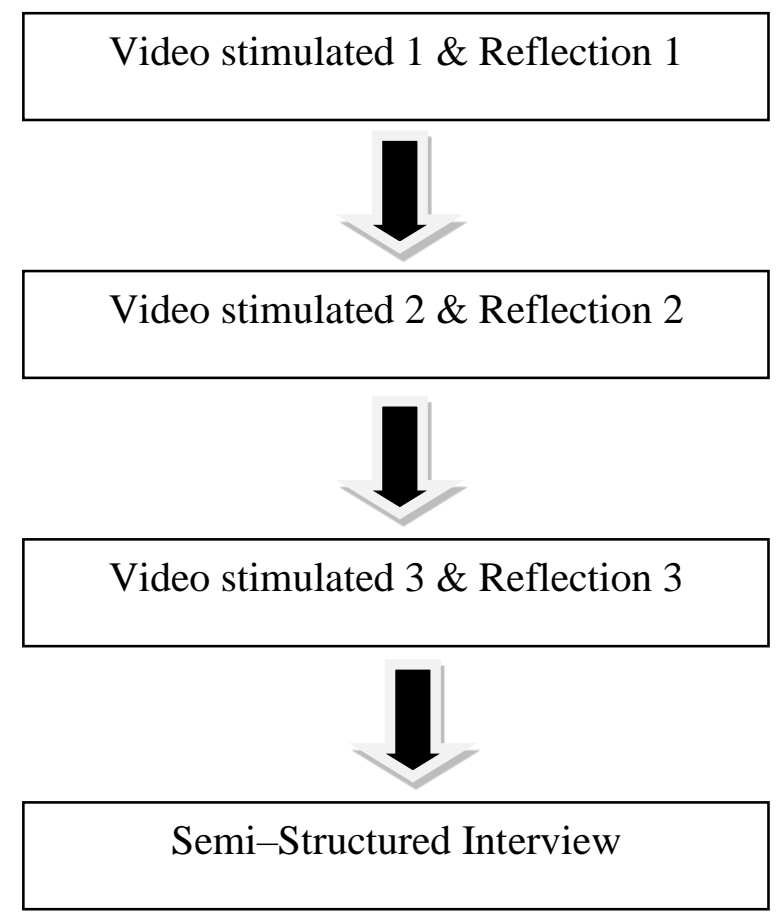

Figure 1. Overview of video-stimulated reflection procedure.

The procedure in collecting the data as listed:

The researcher explained to the participants the procedure of collecting the data in order to get their consent to be recorded when they spoke English. In an effort to make them feeling as comfortable as possible, the interviewer asked their free time to do the interview. They were informed that they would be interviewed after watching their video along writing their own reflections. Then the participants were asked to watch the video that had been recorded and wrote a reflection after watching their recorded video. The researcher took the recorded video from the participants thrice. The video-stimulated reflection technique was chosen because several studies reported benefits of using video-stimulated reflection in data collection (Li \& Peng, 2018; Yasuko et al., 2014; Zulaiha \& Mulyono, 2018). For instance, video reflection 
facilitates the self-discovery and development of the students according to which actions will improve further (Tripp \& Rich, 2012).

The current study has been adopted method from Yasuko et al., (2014) where the types of tasks are documentary. The participants were instructed to give memorized speeches with three different repetitions and preparations. They composed a three-paragraph presentation, consisting of an introduction, body, and conclusion, between 180 and 200 words as a whole. The participants were asked to watch their video recordings of speaking performances after the researcher took their speaking- three times. The researcher asked the participants to write their reflection to identify their performances' weaknesses and strengths as well. Our intention was to evoke the impressions of the students as to whether the evaluation of video-stimulated reflections was more effective in assisting learning than face-to-face feedback (Gong, Kawasaki, Yeung, Zhang, \& Dobinson, 2019).

After reviewing recorded video thrice, the researcher delivered a semi-structured interview with each participant for around 15 minutes. Schultze and Avital (2011) indicated that one of the essential purposes of doing the interview is to provide an insight into the reality of people's lives based on their own experience and to understand how to use video stimulation affects the process of improving their speaking. The data from the interview and the reflection journal would be compiled for further study afterwards. The interview information and reflection results would be processed through thematic analysis. The analysis involves a textual review of the reflective journal, and semi-structured interview answers. In addition, this research adapts Yasuko et al., (2014) content analysis, which has the relevant code, as shown in Table 2:

Table 2. Content analysis by Yasuko et al. (2014)

\begin{tabular}{|l|l|}
\hline Voice Control & Stabilize voice control when speaking \\
\hline Body Language & Provide comfort when speaking \\
\hline Effectiveness & Effectiveness to improve student speaking \\
\hline
\end{tabular}

\section{FINDINGS}

The purpose of this study was to discuss EFL students' perceptions after watching their reflection video. Several contributing factors for the students were: (a) Voice Control (b) Body Language (c) Effectiveness.

\section{VOICE CONTROL}

In communication, voice control serves as a bridge between message content and meaning from one person to another.

Based on the results of interviews and reflection journals, the participants stated that voice control was the most important thing during the speaking. They also mentioned that intonation, pronunciation, and appropriate volume were the main elements in voice control. Joni, for example, expressed his perceptions related to intonation: 
"From my video, I will learn to use consistent intonation so that the listener will not get me wrong while interpreting the words or phrases I say." (Reflective Journal 1 Lines, 2-3 (S2)).

In addition, the pronunciation was identified to manage the sound well, so it was pleasing to listeners. As expressed by Khansa:

"The pronunciation is really important, because if the pronunciation is unclear the information will not reach to the listener." (Interview Lines 24-25 (S6))

Another element, appropriate volume when speaking, is an expressive voice full of meaning. As expressed by two other students, Rizki and Khansa, suggesting that:

"Speaking out loud is very influential in my view, and the more we talk clearly, the more comfortable we are." (Interview Lines 17-18 (S3))

"After watching this video, my voice that comes out when I speak is loud enough to keep the conversation going well." (Reflective journal 2 Lines, 1 (S6))"

In this section, students show that the results of using video-stimulated reflection significantly improve voice control when speaking both directly, or speaking in front of the camera. The results of this finding suggest that the video helps students get a specific point of view. As described by these students, there is an interesting fact that voice control can affect someone's confidence in speaking. Therefore, students believe that by using good pronunciation, an interpretation of speaking can be delivered well. The use of an appropriate volume can also affect the expression while speaking.

\section{BODY LANGUAGE}

This study also revealed that body language provides comfort when speaking because it can pursue students to improve their speaking performance. When they try to use gesture, hand and eyes contact, it can be a type of nonverbal communication used for communicating or transmitting the information. For example, Ervinda stated:

"In my opinion, it is also very crucial. For example, we don't enjoy our rigid body language when talking. On the contrary, if we are relaxed, it means we can speak fluently, and our body language looks very comfortable." (Interview Lines 39-45(S5))

Furthermore, hand positions can stimulate the students more relaxed, and the message to be communicated should have a clear interpretation when they oral communication. Some students, such as Ravi and Joni said:

"I just feel body language is the actual influence on improving speaking. When our hands' move, it can give a clue about what we want to talk about. For example, talking about objects, there are things and objects that we hold to make instructions for us if we don't know what to say, or we forget what the word is." (Interview Lines 64-67(S1)) 
"The position of my hand is responsive, and it makes me more relaxed in offering ideas to discuss and focusing my eyes on the camera, and sometimes looking up if I forget a little bit about the ideas to convey." (Reflective journal 2 Lines, 10-13 (S2))

The last perception was eye contact can also provide a sense of comfort when speaking to another. Ervinda believed:

"I usually move my body because it can increase my confidence in explaining something and reduce my panic. The position of my eye that focuses on the camera, and occasionally face other direction, so the interlocutor sees, and understands what I mean as well." (Reflective journal 1 Line 9-10 and 13-14 (S5))

The findings in this section explained that the students agree if body language is one of a pivotal part to improve speaking skills. It was proven by the results of the interviews which stated while students watching their video, they encountered such comfort by moving their hand, or eyes. At that time, they could speak English comfortably. Furthermore, the students mentioned that body language could provide more message.

\section{EFFECTIVENESS}

The effectiveness is the effect or consequence of conformity in an activity of a person carrying out a task with the intended goal. If something is considered successful, it indicates that it has an anticipated result. In the interview and reflecting journal, it was revealed the benefit of reflection through video is that video can provide effectiveness in vocabulary to improving speaking. With regards to vocabulary, Khansa expressed:

"After watching this video, I started to use a lot of vocabularies that fit the theme of the video. My grammar is good enough, [I only a little bit was mistaken when delivering the grammar]. (Interview 2 Lines, 21-23(S6))

"In this video, I'm planning [to memorize more] vocabulary of what I want to talk about, in this episode. So that more information can be communicated and I've made a lot of improvement since I find new words of vocabulary in the content that I communicated. (Reflective journal 2 Lines, 11-12 and 13-14 (S6))"

Besides, these students stated that the use of video could be a learning material for them to enhance speaking skills, and they can play the video a few times to see their performance. As evidenced in the following quotation:

"I am not really confident to speak English even in front of the camera and my [own] friend. (Reflective journal 3 Lines, 24-26 (S5))"

"Using this video has encouraged my speaking skill. Because I've come to know what, and how to describe in English (Reflective journal 1 Line 18-19 (S2))" 
"Pretty successful [in reflecting using a video] because we know our mistakes in the past, and we can learn our weaknesses. [We can also] revise the weaknesses we made in previous videos. (Interview Line 92-94(S1))"

"It is effective, although something like that needs encouragement. The procedure is not forced, but it is a must. So, it allows us to keep speaking (Interview Line 95-97 (S5))"

Thus, the students assured the benefit of reflecting through video could compare their last performance to their previous performance. Then, they understand the progress of vocabulary improvement and identify weaknesses within the strengths to reduce similar errors. Furthermore, the result of effectiveness by viewing video recordings is one of the efforts made in order to achieve the desired results.

\section{DISCUSSION}

This study was designed to determine the effect of using video-stimulated reflection on improving EFL student majoring in English Education in a private university in Jakarta. This research has a great aim to develop the quality of speaking in learning sessions, especially developed the quality of EFL students' speaking. Therefore it can be assumed that videostimulated reflection supports students to develop quality in learning, and provide facilities for students to practice improving their abilities.

As mentioned before, the students showed evidence of improvement in speaking, such as voice control, body language, and level of effectiveness. Watching themselves speaking English in the video can develop more domain such as vocabulary memorization where those concepts can use as information, and the meaning of the words conveyed. It is contradictory with Silverman (2013)'s finding that the students felt there was a lack of improvement for those who did not reflect they speaking using video reflection. The results were also supported by students who informed that there was a significant improvement of the video stimulated reflection of students in speaking. Overall, video-stimulated reflection definitely has a positive impact on improving speaking skills among EFL students.

The results of the current study also discovered that students experience the benefits of improving voice control when they re-watch the video-stimulated reflection rapidly. The students can find out both advantages and disadvantages of their vocal processing when speaking, especially on their daily communication use. A study by Yasuko et al., (2014) establish that word include sound and appearance such as voice, expression, speech, presentation, were used to explain some aspects of performance that they imitate to enhance their speaking performance. Interestingly, when they speak by adjusting the level of intonation, pronunciation and appropriate volume, the message to be conveyed to the interlocutor will be heard clearly so that the communication will be going well.

Other results of this study indicate that using their body language to communicate can provide a sense of relaxation when they feel panic, and can help clarify the meaning of the message to be conveyed. Body language can also comfort and promote self-confidence when they communicate with other people. It refers to the previous study by Li1 (2015) whom students watch the video reflection; they consciously or unconsciously will repeat what they discuss and do in the video. More importantly, their speaking skills can be enhanced by watching their own videos and making non-verbal comparisons such as eye contact, body language, hand gestures and facial expressions. This means body language also has a potential benefit on learning to speak English.

The data analysis also revealed that the video reflection had an effective impact on memorizing new vocabulary. It could also be used as materials to correct mistakes and

Received August 11, 2020; Revised August 20, 2020; Accepted September 7, 2020 
weaknesses that occurred previously in speaking skills. This far, research has shown the advantages and effectiveness of implementing video reflection in speaking foreign languages, resulting to high students' enthusiasm so it can provide varied interpretation, and motivation in language learning (Ambard \& Ambard, 2012). Therefore, using video-stimulated reflection as an instructional tool for EFL speaking, students can indirectly gather various kinds of knowledge to overcome deficiencies that exist in themselves to improve their speaking skills.

\section{CONCLUSION}

To sum up, our current study aims to enrich the literature on video-stimulated reflection by exploring six Indonesian EFL students. We conduct their recorded video while speaking English, their interview results and written reflections. After we analysed the whole data from the interview results and written reflections, three elements do exist. These three elements are voice control, body language, and the effectiveness of using video-stimulated reflection showed up to assist students' speaking skills. However, our current study has a limitation. This study was conducted online due to pandemic COVID-19 which consequently could not provide maximum directions. Although the limitation lies, the application of this strategy videostimulated reflection also provides benefits. The benefits can be experienced by the students that they can improve their speaking skills. While for the teachers, it gives them insight about their students' speaking skills levels so the teachers know what treatment needs to be disseminated to their students. In order to explore their ability and motivations, future studies are suggested to concentrate on various subject areas or various education level.

\section{REFERENCES}

Ambard, P. D., \& Ambard, L. K. (2012). Effects of narrative script advance organizer strategies used to introduce video in the foreign language classroom. Foreign Language Annals, 45(2), 203-228.

Boud, D., \& Walker, D. (1998). Promoting reflection in professional courses: The challenge of context. Studies in Higher Education, 23(2), 191-206.

Boyle, R. (1996). Modelling oral presentations. ELT Journal, 50(2), 115-126. https://doi.org/10.1093/elt/50.2.115

Carlone, H. B., Scott, C. M., \& Lowder, C. (2014). Becoming (less) scientific: A longitudinal study of students' identity work from elementary to middle school science. Journal of Research in Science Teaching, 51(7), 836-869.

Gong, Q., Kawasaki, K., Yeung, W. L., Zhang, G., \& Dobinson, T. (2019). Students' perceptions of the use of video recording in additional language oral assessments. Multiliterate, Multilingual, Multimodal, Multilingual Education, 133-152. https://doi.org/10.1007/9783-030-01255-7_8

Kaur, D., Yong, E., Zin, N. M., \& DeWitt, D. (2014). The use of videos as a cognitive stimulator and instructional tool in tertiary ESL classroom. Malaysian Online Journal of Educational Technology, 2(3), 32-41.

Received August 11, 2020; Revised August 20, 2020; Accepted September 7, 2020 
Li, A., \& Peng, T. (2018). Observing 'myself' in the video: Fostering reflective practice in oral presentation training. Advances in Language and Literary Studies, 9(3), 138-144.

Li1, Y., Gao1, Y., \& Zhang1, \& D. (2015). To speak like a TED speaker-a case study of TED motivated English public speaking study in EFL teaching. Higher Education Studies, 6(1), 53-59. https://doi.org/10.5539/hes.v6n1p53

Mary, E. (2013). The pedagogical balancing act: Teaching reflection in higher education. Teaching in Higher Education, 18(2), 144-155.

McNulty, A., \& Lazarevic, B. (2012). Best practices in using video technology to promote second language acquisition. Teaching English with Technology, 3(12), 49-61.

Okada, Y., Sawaumi, T., \& Ito, T. (2017). Effects of observing model video presentations on Japanese EFL learners' oral performance. Electronic Journal of Foreign Language Teaching, $14(2), 129-144$.

Okada, Y., Women, S., Sawaumi, T., \& Ito, T. (2017). Effects of observing model video presentations on Japanese EFL learners' oral performance. Electronic Journal of Foreign Language Teaching, 14(2), 129-144.

Schultze, U., \& Avital, M. (2011). Designing interviews to generate rich data for information systems research. Information and Organization, 21(1), 1-16. https://doi.org/10.1016/j.infoandorg.2010.11.001

Silverman, R. (2013). Investigating video as a means to promote vocabulary for at-risk children. Contemporary Educational Psychology, 38(3), 170-179.

Tripp, T., \& Rich, P. (2012). Using video to analyze one's own teaching. British Journal of Educational Technology, 43(4), 678-704. https://doi.org/10.1111/j.14678535.2011.01234.x

Yasuko, O., Takafumi, S., \& Takehiko, I. (2014). How do speech model proficiency and viewing order affect japanese EFL learners' speaking performances. Computer-Assisted Language Learning-Electronic Journal, 19(2), 61-81.

Zulaiha, S., \& Mulyono, H. (2018). Preservice EFL teachers' talk during a teaching practicum at a lower secondary school: A report on video-stimulated reflection ( VSR ). Argentinian Journal of Applied Linguistics, 6(1), 44-60. 